\section{International Journal of \\ Innovative Research in \\ Education}

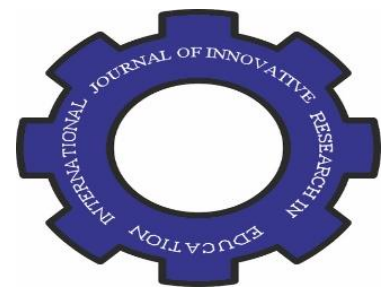

Volume 7, Issue 1, (2020) 16-25

$\underline{\text { www.ijire.eu }}$

\title{
Media and educational technology in Nigeria: Managing the broadcast programmes of Radio Nigeria Globe FM towards girl child education
}

\author{
Hashim Sabo Bello*, Abubakar Tatari Ali Polytechnic Bauchi, Department of Business Administration and \\ Management, School of Management Sciences, Bauchi, Nigeria \\ Sa'adatu Umar Idris, Federal Radio Nigeria Globe FM, Bauchi, Department of Programmes, Bauchi, Nigeria \\ Abubakar Bappayo, Abubakar Tatari Ali Polytechnic Bauchi, Department of Mass Communication, School of \\ General Studies, Bauchi, Nigeria
}

\section{Suggested Citation:}

Bello, H. S., Idris, S. U. \& Bappayo, A. (2020). Media and educational technology in Nigeria: Managing the broadcast programmes of Radio Nigeria Globe FM towards girl child education. International Journal of Innovative Research in Education. 7(1), 16-25. https://doi.org/10.18844/ijire.v7i1.4715

Received from January 25, 2020; revised from April 20, 2020; accepted from June 20, 2020.

Selection and peer review under responsibility of Assoc. Prof. Dr. Zehra Ozcinar Teacher Training Academy. ${ }^{\circ} 2020$ Birlesik Dunya Yenilik Arastirma ve Yayincilik Merkezi. All rights reserved.

\begin{abstract}
This study was carried out in Shall and Yalwa village areas of Tafawa Balewa and Dass local government areas, respectively, in Bauchi state (Nigeria) with a strong view of determining the efficacy of media in education towards managing girl child issues in Nigeria. An intensive oral interview was employed in data collection from staff of Radio Nigeria Globe FM, as well as the students and staff of schools and the parents from both Shall and Yalwa villages. The study employed a survey design and utilized a documentary approach to obtain data. Descriptive statistics (means, frequency and percentages) and $\chi^{2}$ were used in analysing the socio-economic characteristics of the stakeholders in girl child education. The results revealed that $91.2 \%$ of the responses hold the opinion that the strategies used by the Radio Nigeria GlobeFM to intervene in girl child education proffered unique and far-reaching benefits in educating the girl child to discover herself and associate with the right group of people, marry the right kind of men, make the right contributions and help men develop sustainable environment. The results also revealed that $61.8 \%$ of the responses hold the belief that Radio Nigeria GlobeFM programmes on the Nigerian girl child are much effective, educative and relevance. The study suggested that the adoption of educational technology strategies is a way forward to managing girl child education, which is a progressive approach in Nigeria, there by setting up booster stations and organise village rallies, discussion programmes with women as moderators to serve as role models for young girls, radio links programme to initiates talks with parents and other stakeholders, initiate kiddies programme fashioned after the likes of the world of children and finally strategies for career guidance.
\end{abstract}

Keywords: Broadcast programme, educational technology, girl child, management, media.

* ADDRESS FOR CORRESPONDENCE: Hashim Sabo Bello, Abubakar Tatari Ali Polytechnic Bauchi, Department of Business Administration and Management, Bauchi, Nigeria

E-mail address: hashimsabo@gmail.com 
Bello, H. S., Idris, S. U. \& Bappayo, A. (2020). Media and educational technology in Nigeria: Managing the broadcast programmes of Radio Nigeria Globe FM towards girl child education. International Journal of Innovative Research in Education. xx(x), 016-025.

\section{Introduction}

As the world increasingly becomes a global village, it is widely accepted that the social and technological advancement of any nation is to a large extent dependent upon the educational development of its citizens. And for this to be achieved, the relevance of media (in facilitating education) and the education of the girl cannot be over emphasised in our society as it does not only improve the health of the family but affects the economic well-being of the country. In line with this thinking, Akinmade (1997) observed that this can be seen from the behaviour of an educated girl who is refined, disciplined, a competent mother in all societal aspects, a knowledgeable family planner, a more productive and better paid worker, an informed citizen and a skilful decision-maker. In defence of women, Ezeoman (1987) also argued that women have always contributed significantly to the economic, social and political lives of their countries, even though their contributions have not always been topics of discussion among scholars and national development planners.

Although the United Nations Convention on the rights of the child (CRC) stipulates in Article 18 that every child has a right to education and that the state's duty is to ensure that primary education is free and compulsory, to encourage different forms of secondary education accessible to every child, and to make higher education available to all on the basis of capacity, 140 million children in the world still do not attend schools and two-third of them are girls (Hawley et al., 2000). Education cannot take place without one form of communication or the other. Communication involves the process of sending and receiving information or messages. For messages to get transmitted (sent or received), they must pass through a channel, smedium or a transmitter. Thus, media are channels through which messages, information, ideas and knowledge are conveyed and or disseminated (NTI, 2005).

Medium (or media in plural) is used in general to define a means of communication. It refers to anything that carries information between a source and a receiver. Media programmes with educational intent are means of communication used to disseminate messages with awakening goal. In spite of the media campaign on the importance of education and the fact that it is free for all, Umar (1997) posited that there are a number of school age children who do not attend primary school, either because they have not been enrolled or have dropped out for one reason or the other. In both cases, female children constitute the majority as indicated by statistics of enrolment in Nigerian primary and secondary schools. Rabiu (2014) observed that as a way of encouraging girl child education for national development, governments should support this campaign through funding and employing people who can go the grassroots for sensitisation. They also need to partner with other nongovernmental organisations, like the girl child concern, to champion this course. The federal government, through the universal basic education (UBE) programme, is making an effort at accelerating girl child education, and the programme has made some progress in increasing the school enrolment for girls in northern Nigeria.

The popular saying is, if you educate a man you educate an individual, but if you educate a woman you educate a family. Although, extreme poverty, mass illiteracy, large-scale ignorance, high maternal mortality and fertility rates, child wastages and lack of access to health, education and social services may sound far and fictional, but to many indigenes and visitors to Shall and Yalwa village areas in Tafawa Balewa and Dass local areas, respectively, of Bauchi State (Nigeria), they are part and parcel of everyday life. The world, realising that these problems are not unique to Shall and Yalwa, met in September 2000, in the United Nation Organisation assembly and came up with Millennium Development Goals (MDGs), which had an eight-point agenda, including the eradication of the worse kinds of poverty, UBE and gender equality. The realisation of the objectives of these MDGs is hinged just on one thing.

\section{The concept of girl child from the home into the school and society}

This research work attempts to explore issues from the home into the school and society at large that hinder the progress of education of the girl child in Nigeria and seeks to redress through the 
provision of qualitative education through multiple channels, including agencies such as media. It is clear that the media worked with other variables to bring about change, either at the individual level or at the group or social levels. Media serves as a major channel through which the roadmap for the Nigerian education sector is disseminated; these include: (i) access and equity; (ii) standards and quality assurance; (iii) technical and vocational, education and training; and (iv) funding and resource utilisation.

For the purpose of this work, a review of the agenda-setting theory is of paramount importance as it 'proposes that the facts which people know about public issues tend to be those which the mass media presents to them. Also, the significance which they ascribe to the same issues tends to be proportionate to the amount of attention given to the same issues in the media' (Anaeto et al., 2008). Here, it is assumed that the media sets the agenda for our general discussion. The media may not always determine what we think, but what we think about. Although we have the right to think what we want to think, but surprisingly, we tend to think most of those things the media highlights as important.

\section{Girl child in the Nigerian family and school environment}

\subsection{The girl child}

Chibiko (2009) refers a girl child as a biological female offspring from birth to 18 years of age. This is the age before one becomes a young adult. This period covers the crèche, nursery or early childhood (0-5 years), primary (6-12 years) and secondary school (12-18 years). During this period, the young child is totally under the care of the adults, who may be her parents or guardians and older siblings. It is made up of infancy, childhood, early and late adolescence stages of development. During this period, the girl child is malleable, and builds and develops her personality and character. She is very dependent on the significant others, those on whom she models her behaviour, through observation, repetition and imitation. Her physical, mental, social, spiritual and emotional developments start and progress to get to the peak at the young adult stage.

In Nigeria, it is the practice that women and children are responsible for keeping the environment clean. The girl child assists her mother to keep the surroundings clean excluding the male child. She is responsible for fetching water which makes her face great risk of water-borne diseases, like guineaworm infection, typhoid and cholera, if the water is polluted. According to an instructional manual prepared by women 'Affairs and Social Development of Nigeria' in 1996, the girl child is saddled with a lot of responsibilities in the home and environment. This hard labour sometimes prevents the girl child from getting educated because the parents consider her in dispensable to such responsibilities (Musa, 2000). Hence, she is left out in the decision-making, utilised at homes without due remunerations, kept as a home keeper and never allowed to earn a living for herself, and used by men as a wife, by children as a mother, by other women as a house girl and by men as a bed mate (Fishel, 1998; Oleribe, 2002a,2002b;Sarwer\& Sheikh, 1995).

\subsection{The girl child in a Nigerian family}

The girl child from birth, if she survives, may be considered a costly guest in her own home. Her schooling is a waste of time and money and she is diligently trained only for her prescribed role in her soon to be family as a bearer of many children and source of free-labour. Her health is at risk and her care expenses are high because of early pregnancy; if she survives that, the large number of children she is likely to bear strains the family economy and often the land (Girls World Report, 2000). The summarises the predicament of the girl child as conceived by some families in some parts of Nigeria, where a girl born into the family is received with mixed fetching, while a baby boy is considers a source of joy and pride to such families (Musa, 2000). 
Bello, H. S., Idris, S. U. \& Bappayo, A. (2020). Media and educational technology in Nigeria: Managing the broadcast programmes of Radio Nigeria Globe FM towards girl child education. International Journal of Innovative Research in Education. xx(x), 016-025.

Musa (2000) further opined that some parents hold the view that it is better to have more boys than girls. Therefore, it is better for them to spend more time and money on the education of boys than girls. She also observed that illiteracy begins as a sad fact of daily life for millions of children who are more often than not girls. The reasons are numerous. According to Girls World Report (2000), for girls, their gender alone may keep them home, locked in subsistence chores or so isolated in the classroom that they become discouraged and dropout.

In Nigeria, fewer girls than boys are still being sent to school. In some parts of the country, more girls than boys are withdrawn from school for early marriage and the fact that they often assist in housework than boys they may not have time study when they come home from school. Free access to a quality education is the right of every child without expectation or discrimination on gender basis. The vision of educational quality enshrined in the CRC extends to the issues of gender equality, equity, health and nutrition. It also demands that schools should be zones of safety for children, so as to ensure decent sanitation facilities and respectful environments for girls.

\subsection{The girl child in a school environment}

Girl child education is a sine qua none to the realisation of total women empowerment and emancipation across the globe, and involves the formal (and sometimes informal) training of a girl child in knowledge and skills of daily living (Oleribe, 2000a). Denial of girl child education (GCE) is the commonest manifestation of neglect of child education, the most retrogressive of all forms of child neglect (Oleribe, 2000a, 2000b). It refers to the inability or refusal of a system to provide the girl child an opportunity for a qualitative and timely education, and is perpetrated by the government, parents/guardians, teachers and the society.

Musa (2000) observed that in the lowest income countries, such as Nigeria, it was reported that there exists a pervasive grimness in the physical environment and the intellectual atmosphere of learning environment, i.e., the school. Overcrowding is common and compounding physical problems affect girls, such as distance from home and lack of toilet facilities. She further opined that some teachers discourage girls with the wrong beliefs that they are not as intelligent as boys. Others discourage them from choosing certain school subjects because they think, wrongly, that girls should do only subjects which would make them good housewives and mothers. One prime gauge of educational quality is how narrow the classroom gender gap is. A school is child-friendly study place when both girls and boys find it a safe, welcoming and healthful environment, centred on the rights of the child and where teachers demonstrate respect for those rights. A place where students discover that education is not only relevant to their lives, but is also a source of joy. The society, such as the Nigerian society, should try to discourage early marriage and encourage completion of school by eliminating all the cultural or societal dogma that girls educated end up in the kitchen or the misconception that educated girls do not make good wives and mothers.

In the schools, lack of sufficient protection for the girl child against sexual harassment from some male students and teachers results in poor performance and even dropping out of school. It is against this background Mohammed (2011) argued that: 'Girl, more often than Boys, is consistently denied opportunities to go to school for an array of reasons including those related to HIV/AIDS, gender discrimination, domestic demands, traditional practices, safety concerns and inappropriate physical and learning environment at school.'

\section{Media intervention as a drive way for managing educational technology}

The views of eminent scholars portray management as a social process involving planning, organising, coordinating, controlling, unifying formally and informally organised groups, motivating and integrating ideas to achieve the organisation's goal. This involves the identification of an educational problem, and the planning towards it. Fundamental issues in society like those concerning the management of problems and the processes of change which Education for All/GCE seek to do all 
turn for the mass media. This is rooted in the normative theory of media which examines how the 'media ought to work if certain social values are to be observed and attained' (McQuail, 2000). In aiding development, the media helps to reorient audiences in order to prepare the minds of people. In line with this argument, the media 'plays a part in sharing and legitimising media institutions' and they influence the expectations concerning the media that are held by complementing institutions and those of the media audiences themselves (Alhaji,2010).

The role of the mass media, i.e., prints (newspapers, magazines, and outdoor channels), broadcast (radio, television, home videos, and cinema) and the internet in girl child education has been essential. The mass media exercises immense influence on the girl child's lives as its serve as vehicles for passing messages to the target audience or public. The messages created such as the child-girl education are conveyed to the public. The media, according to McQuail (2000), are also primary sources of definitions and images of social reality and vast sources of shared reality. This is important to the articulation of development means and implementation of developmental programmes because the mass media programmes provide diverse, sometimes, conflicting but necessary, ideas needed to shape development policy. McQuail also argues that 'the media are focus of leisure time interest and they provide the "shared culture" for most and more people than any other single institution'.

Radio is today a vital medium for both domestic and international communication: The medium, which had Marconi as the first in the line of contributions, made history in 1892 when a Kentucky, former Nathan Stubblefield, transmitted the first voice sound via wireless. The subsequent perfection of this discovery and the advent of the satellite technology gave radio its current status. Since 1920, the short-wave radio has been employed for its value as a tool of broadcasting. Before that (i.e., 1920), most radio broadcasts were by either the Navy or amateur hobbyists. Adolf Hitler and Joseph Goebbels used radio for propaganda during the Second World War, while other nations employed it to counter their propaganda. For example, the propaganda services of the German Reich had to contend with the British Broadcasting Corporation (BBC) for public acceptance during the period (McQuail, 2000).

In the colonial era, the colonial powers employed radio to indoctrinate the natives. For example, the $\mathrm{BBC}$ regularly relayed its programmes to natives in the colonies through reinfusion boxes distributed to subscribers. Even now radio is widely used for propaganda and to promote domestic and foreign policies objectives by every country. Indeed, it is on record that radio is the most ubiquitous of the mass media in the world. According to the report, there is an estimated one billion receivers (i.e., an average of approximately one for every four persons on earth). It states that in development countries radio is arguably the only true mass medium.

The Radio Nigeria GlobeFM previously called Pearl of TourismFM transmits its programmes behind old Dass Park, new GRA Bauchi, Bauchi State of Nigeria, since its inception in 2003. It started operation with only three departments which are, namely the news and current affairs department, the programme department and the current affairs department with a total number of eight staff and now the number of staff has raised up to 68 staff. Some of the programmes of the said FM station includes current affairs, socio-economic as well as political programmes as Ilimigishirinrayuwa, Yaramanyangobe, GaFiligaDoki, WokokiBiyarmasuTashe, News production, Bauchi State in the National Dailies, Newspapers Teasers, etc. The programmes are broadcasted in the major languages of Bauchi broadcast programmes, which are Hausa, English, Fulfulde, Yoruba and Pidgin English, etc.

The media, such as television, radio and newspapers, collectively together with the people involved in their production has played a vital role in facilitating girl child education programme. In the first instance, the media, the like of the Radio Nigeria GlobeFM as the case in point, has tremendously and positively contributed to the unique and far-reaching benefits of girl child education through its broadcast programmes such as children fun-times and ilimigishirinrayuwa, etc. which bordered on the girl child. These programmes give a true and proper image of educating the girl child to discover herself, has boosted their self-respect and make them the mothers and wives that the world would love. Moreover, Hawleyet al. (2000) posited that the media-based crusades and enlightenment 
programmes carried out and on regular basis has indeed 'generated awareness of the disadvantaged situation of girls'. In line with this thinking, Chibiko (2009) posited that the media often buttress an adage that says: 'educate a man, you educate an individual, but educate a woman, you educate a nation'.

\section{Materials and method}

This study was carried out in Shall and Yalwa village areas of Tafawa Balewa and Dass local government areas of Bauchi state (Nigeria) with a strong view of determining the role of media intervention in managing and educating the girl child issues in Nigeria. In conducting the research, an intensive oral interview was employed. The decision of the researcher to use the interview method was due to the fact that the procedure involved in the coverage and attitude of questionnaire most of the time does not receive the necessary personal attention and does not yield result. Secondly, the method of using available records stands the best effective way of obtaining a factual data. The study employed a survey design and utilises documentary approach to obtain data. The scope has a population of 95 respondents drawn from Radio Nigeria GlobeFM, as well as students, teachers and parents from both Shall and Yalwa villages were individually engaged in an unstructured and structured interview. Similarly, the data collection from the records available was straight forward. All data collected were analysed using standard statistical methods.

\section{Results and discussion}

As a matter of fact, all information or data (either numerical or non-numerical) and tables shown in the task are based on the primary and secondary data gathered, which the researcher digested and brainstormed to present the best effective way suitable for the interpretation of results.

\begin{tabular}{lcc}
\hline \multicolumn{1}{c}{ Variable } & Frequency & Percentage \\
\hline Media practitioners & 47 & 50 \\
Non-media practitioners & 48 & 50 \\
Total & 95 & $100 \%$ \\
\hline
\end{tabular}

Field survey (2011).

Hence Table1shows that 34 respondents representing $50 \%$ of the responses are drawn from the Federal Radio Nigeria GlobeFM, while 34 others representing the remaining 50\% were drawn from the students, teachers, parents and guardians, who are believed to be the stakeholders in the delivery of the girl child education programme. By implication, the $50 \%$ responses from the media practitioners as well as the $50 \%$ from other educative agents' responses showed a balance in the media interventions in girl child education. The responses on sexes showed that 49 respondents representing $72.1 \%$ of the responses are male, whereas 19 respondents making up $27.92 \%$ of the responses are female. By implication, this shows that the research was conducted in male-dominated societies, i.e., media and non-media groupings as a case in point. The educational parameters of the respondents shows that four respondents representing $5.9 \%$ of the responses are master's degree holders, nine respondents representing $13.2 \%$ of the respondents of the responses are degree/HND holders, 31 responses are holders of the National Certificate of Education, National Diploma and Ordinary National Diploma, seven respondents representing $10.3 \%$ of the responses are secondary school learners, 12 respondents representing $17.6 \%$ are primary school learners and five others representing $7.4 \%$ of the responses never attended formal school. This traces the category of persons across the strata of educational qualifications was subjected to interview.

Data obtain from the stakeholders in the study areas as well as the operating and management staff of Radio Nigeria GlobeFM through structured and unstructured interviews provide avenue for interpretation of result. This implies that a considerable percentage of the target population are conversant, attentive and aware of the programme about the girl child, of which most of the 
responses believe that the strategies used by the Radio Nigeria GlobeFM to intervenes in girl child education bordered on the programme's initiative such as ilimi gishirin rayuwa and children fun-times that has unique and far-reaching benefits of educating the girl child to discover herself and associate with the right group of people, marry the right kind of men, make the right contributions and help men develop sustainable environment. Another set of the responses agreed that initiating programmes that featured prominent women are such strategy used by the Radio Nigeria GlobeFM, devoid of radio links and kiddies programmes. By implication, the opinion expressed herein has gone a long way to agree with the views held by Hawley et al. (2000) that: 'better educated women are better able to manage life in a changing social, economic and cultural environment'.

Table 2. Number of staff in selected workplace

\begin{tabular}{lcccc}
\hline \multicolumn{1}{c}{ Work Place } & Male & $\%$ & Female & $\%$ \\
\hline Radio Nigeria GlobeFM Bauchi $n^{=62}$ & 56 & $(99.3)$ & 6 & $(9.7)$ \\
Primary School Shall (Tafawa Balewa) $n^{=5}$ & 7 & $(77.8)$ & 2 & $(22.2)$ \\
Junior Secondary School Shall $n^{=5}$ & 5 & $(100)$ & 0 & $(0)$ \\
Primary School Yalwa (Dass) $n^{=8}$ & 8 & $(100)$ & 0 & $(0)$ \\
Junior Secondary School Yalwa $n^{=11}$ & 10 & $(90.9)$ & 1 & $(9.1)$ \\
Total $n^{=95}$ & 86 & $(90.5)$ & 09 & $(9.5)$ \\
\hline
\end{tabular}

Field survey (2011).

Hence, what is known in Table1 earlier is now supported by Table2, showing the overall number of staff across the various workplaces in the research area, which obviously proved that the research was carried out in the male-dominated society. Table 2 states that $90.5 \%$ of the total employees in the entire workplace were male, whereas $9.5 \%$ were female. This relates a proposition in favour of male dominance. In contrast to the staff inventory, the student's inventory provides a platform so that much can be deduced as presented in Table 3 .

Table 3. Distribution of primary pupils and secondary students in Shall

\begin{tabular}{lcccc}
\hline \multicolumn{1}{c}{ Class } & Boys & $\%$ & Girls & $\%$ \\
\hline Primary I $n^{=50}$ & 29 & $(58)$ & 21 & $(42)$ \\
Primary II $n=78$ & 41 & $(52.6)$ & 37 & $(47.4)$ \\
Primary III $n=50$ & 31 & $(62)$ & 19 & $(38)$ \\
Primary IV $n^{=50}$ & 20 & $(40)$ & 30 & $(60)$ \\
Primary V $n^{=50}$ & 19 & $(38)$ & 31 & $(62)$ \\
Primary Vi $n^{=36}$ & 19 & $(52.8)$ & 17 & $(47.2)$ \\
Secondary I $n^{=37}$ & 23 & $(62.2)$ & 14 & $(37.8)$ \\
Secondary II $n=40$ & 27 & $(67.5)$ & 13 & $(32.5)$ \\
Secondary III $n=52$ & 26 & $(50)$ & 26 & $(50)$ \\
Total $n^{=443}$ & 235 & $(53)$ & 208 & $(47)$ \\
\hline
\end{tabular}

Field survey (2011).

Obviously, taking into account Table 3, out of 443 students in both the primary and secondary school at Shall, 235 (53\%) were boys and 208 (47\%) were girls. With the encouraging enrolment of girls, this implies that the broadcast programmes of the Radio Nigeria GlobeFM have impacted positively on the plight of the girl child in Shall village area. This has proven that the Radio Nigeria GlobeFM programmes on the girl child are much relevant, educative and effective, thereby implying that the Radio Nigeria GlobeFM is indeed a partner in progress regarding media interventions in managing and educating the girl child in Nigeria.

Table 4. Distribution of primary pupils and secondary students in Yalwa

\begin{tabular}{lllll}
\hline \multicolumn{1}{c}{ Class } & Boys & \multicolumn{1}{c}{$\%$} & Girls & \multicolumn{1}{c}{$\%$} \\
\hline Primary I $n^{=50}$ & 20 & $(40)$ & 30 & $(60)$ \\
Primary $I I n=60$ & 35 & $(58.3)$ & 25 & $(41.7)$ \\
\hline
\end{tabular}


Bello, H. S., Idris, S. U. \& Bappayo, A. (2020). Media and educational technology in Nigeria: Managing the broadcast programmes of Radio Nigeria Globe FM towards girl child education. International Journal of Innovative Research in Education. xx(x), 016-025.

\begin{tabular}{lllll}
\hline Primary III $n^{=60}$ & 29 & $(48.3)$ & 31 & $(51.70$ \\
Primary IV $n^{=65}$ & 29 & $(44.6)$ & 36 & $(55.4)$ \\
Primary V $n^{=65}$ & 25 & $(38.5)$ & 40 & $(61.50)$ \\
Primary VI $n^{=40}$ & 22 & $(55)$ & 18 & $(45)$ \\
Junior Secondary I $n^{=158}$ & 93 & $(58.9)$ & 65 & $(41.1)$ \\
Junior Secondary II $n^{=72}$ & 39 & $(54.2)$ & 33 & $(45.8)$ \\
Junior Secondary III $n^{=68}$ & 34 & $(50)$ & 34 & $(50)$ \\
Total $n^{=638}$ & 326 & $(51.1)$ & 312 & $(48.9)$ \\
\hline
\end{tabular}

Field survey (2011).

Thus, Table 4shows that out of 638 total number of students in both the primary and secondary school at Yalwa, 326 (51.1\%) were boys and 312 (48.9) were girls. This depicts the encouraging enrolment of girls into our schools; so, this implies that the broadcast programmes of the Radio Nigeria GlobeFM has positively impacted on the plight of the girl child in Yalwa village area. In essence, the Radio Nigeria GlobeFM participated in the girl child education through initiating discussion programmes bordering the GCE, thereby creating awareness and mobilising people about the short and long-run benefits of the girl child's education.

To sum up the above experience, it can be deduced that the two villages (Shall and Yalwa) has felt the impact of the broadcast programmes of Radio Nigeria GlobeFM in intervening to solve some problems (i.e., girls who ought to be hawking several wares and consumables during school hours along the roads and neighbourhood are uncommon now in both Shall and Yalwa). The Radio Nigeria GlobeFM has in certain ways illuminated the hearts and refined minds to create intellectual empowerment, social empowerment, physical empowerment and mental and psychological empowerment.

\section{Conclusion and recommendations}

It is obvious that the outcomes or findings of this study confirm the words of Annan (2000) of the United Nations, 'No development strategy is better than one that involves women as central players. It has immediate benefits for nutrition, health and savings and reinvestments at the family, community and at last, country level. Educating the girl child is a social development policy that works and a long term investment that yields an exceptionally high return'. Hence, the media interventions in education benefits both boys and girls and ultimately contributes to a mere equal relationship between men and women, and promotes gender equity in education systems, creates a healthy, educated and productive human resource base. It is time, therefore, to begin to do the right thing - to train and educate our girls. It is time to stop the insult of poverty and dependence, and minimise the culture of begging by maximising the great resource GOD gave us in women. It is time to train and retrain the girl child. Accordingly, the girl child, parents, teachers and educative agents must be made to understand the benefits of such education through mass media like newspapers, magazines, televisions and radio. Based on the finding of the study, the following recommendations are made so as to promote effective mass mobilisation, programmes and enlightenment campaigns against sociocultural practices that hinder full development of the girl child: 
1. As the Radio Nigeria GlobeFM initiate programmes sponsored by the task force on girl child education, geared towards enlightening people on the need to educate the girl child and the advantages that would accrue at the end, promoting girl child education through the radio highlights the problems of girl child education, thereby generating awareness and consequently mobilising the people on what should be done. For this to be achieved, the government should establish booster stations that would carry messages to the grassroots and organise village rallies for enlightenment through ward heads. Local news should be broadcasted in local dialects with the help of indigenous producers and reporters.

2. The Radio Nigeria GlobeFM should initiate discussion programmes that will feature women that have made it in the society. The moderators of such programmes should be women and the salient features of how these women have made it should be projected. These women will serve as role models for the young girls.

3. The Radio Nigeria GlobeFM should introduce radio links programme so that talks should be initiated with parents and other stakeholders to discuss the girl child and be made to realise the need and the importance of allowing their girls access to education.

4. The Radio Nigeria GlobeFM, Bauchi, should initiate kiddies programmes fashioned after the likes of the world of children, i.e., the child and society and the jets competition should be organised. The girl child should be prominently featured and girls be made to participate in the panel discussion where their views would be heard. They could also serve as models to those parents who have refused their daughters access to education.

5. The adoption of educational technology via the broadcast programmes of Radio Nigeria GlobeFM as a strategy for a way forward towards girl child education should be made gendersensitive to help alleviate fears held by most females who are conscious of gender discrimination in our society. Career guidance broadcast programmes should be introduced involving women from all walks of life to participate in the counselling and guidance programmes.

\section{References}

Akinmade, C. I. O. (1997). The survival of the girl-child in malfunctioning society. Commissioned paper presented at a Workshop organized by Plateau State Women Commission, January 3rd-4th.

Alhaji, H. H. (2010).Transformationaljournalismaskeytovision2020: Issues and challenges. Yankari Journal, 6,163.

Anaeto, S. G., Onabanjo, O. S., \& Osifeso, J. B.(2008).Models and theories of communication. Baltimore, MD: African Renaissance Books Incorporated.

Annan, K. (2000). Building a partnership for girl's child education. World Education Forum. April 26.

Chibiko, G. O. (2009). Girl-child education in Africa. A keynote address presented at the Conference of the Federation of University WOMWNE of Africa held in Lagos - Nigeria. 16th-19th July.

Ezeoman, C. (1987). The settlement of nomadic ful be in Nigeria implication for education development. The Bemros Press Limited.

Fishel, J. (1998). Educating girls: Population growth's silver butted? Zpa report. (3):3, June $30^{\text {th }}$

Folarin, B. (1998). Theories of mass communication: An introductory text. Stirling-Horde nPublishers (Nig.) Limited.

Gotan, C. (2000). Identifyingobstaclestotheeducationofgirl-childinthenewmillennium: The way forward. Readings in Educational Theory, Vol. II.A publication of the Department of Arts and social science Education. University of Jos, Nigeria.

Haggai, M. P. (2000). Child development in the contemporary family. Readings in Educational Theory, Vol. II.A publication of the Department of Arts and Social Science Education. University of Jos.

Hawley, et al. (2000). Education and the girl-child. NGO Committee on UNICEF. UN Plaza.

McQuail, D. (2000). McQuail's mass communication theory. Sage.

Mohammed, H. K. (2011). Nigeria: the problem of girl-child education (Vol.1(5), p.6). Goshi - The Fortuna Magazine. 
Musa, T. G. (2000). Environmental issues and problems affecting the girl-child in Nigeria: Seeking redress through education. The Jos Journal of Education, University of Jos.

NTI. (2005). PDE102: educational technology. Post Graduate Diploma in Education by Distance Learning Studies, National Teachers' Institute, Kaduna printed by Birani Nigeria Press.

Ocho, L. O. (2005). Issues and concerns in education and life. Institute of Development Studies, University of Nigeria.

Oleribe, O. E. O. (2002a). The concept of child abuse (pp.16-137). An Anti-Child Abuse Society of Africa (ACASA), National War College Press.

Oleribe, O. E. O. (2002b). The fundamentals of child rights (pp.10-110). An Anti-child Abuse Society of Africa (ACASA): National War College Press.

Rabiu, M. (2014). Revisiting girl child education in the North. Pointer Express Newspaper: I.M. Publications. $3(230)$, June 12th.

Sarwer, B., \& Sheikh, M. (1995). The girl-child: a girls' empowerment Initiative in Pakistan. Plan Parent Chall, (2): 37-43.

Stellamaris, U. (2011). Gender inequality in Nigeria. National Review Magazine. Media Review Publications.

Umar, L. K. (1997). Problems and prospects of girl-child education in Nigeria. A paper presented at a workshop on Girl-child abuse and dropout, organized by the Plateau State Women Commission, January 3rd-4th. 